\title{
Source parameters of the May 29, 2004 South Korea earthquake $\left(M_{L}\right.$ 5.2)
}

\author{
Sun-Cheon Park and Jim Mori \\ Disaster Prevention Research Institute, Kyoto University, Gokasho, Uji 611-0011, Japan
}

(Received November 20, 2004; Revised April 22, 2005; Accepted April 25, 2005)

\begin{abstract}
A moderate earthquake with local magnitude $5.2\left(M_{L}\right)$ occurred off the eastern coast of South Korea on May 29, 2004. This earthquake is one of the largest events near the Korean Peninsula since 1978 when instrumental observations began by the Korea Meteorological Administration. We carried out modeling of regional waveforms and deconvolutions using empirical Green functions to estimate source parameters. The results of the regional waveform modeling show a reverse fault mechanism with a hypocentral depth of $8 \mathrm{~km}$ and seismic moment of $5 \times 10^{16} \mathrm{~N} \cdot \mathrm{m}$, which is equivalent to Mw 5.1. Performing the empirical Green function deconvolution, we estimated a fault radius of 1.1 to $1.4 \mathrm{~km}$ and an average stress drop of $13.5 \mathrm{MPa}$, assuming an east dipping fault plane. Assuming a west dipping fault plane, we estimated a fault radius of 1.3 to $2.9 \mathrm{~km}$ and an average stress drop of 6.6 MPa.
\end{abstract}

Key words: Earthquake, waveform modeling, deconvolution, South Korea, empirical Green function.

\section{Introduction}

A moderate earthquake $\left(M_{L} 5.2\right)$ occurred off the eastern coast of South Korea on May 29, 2004. The Korea Meteorological Administration (KMA) reported that the highest intensity was Modified Mercalli (MM) V, in Uljin which is about $70 \mathrm{~km}$ from the hypocenter. This earthquake is one of the largest events near the Korean Peninsula since 1978 when instrumental observations began by KMA (Fig. 1). According to the KMA catalogue, only 5 earthquakes with magnitudes greater than 5 occurred around the Korean Peninsula between 1978 and 2004. $M_{L} 5.2$ and $M_{L}$ 5.0 earthquakes occurred onshore in South Korea in 1978 ( 1 and 2 in Fig. 1), a $M_{L} 5.0$ event occurred off the western coast in 2003 (4 in Fig. 1), and the May 29, 2004 event (5 in Fig. 1) was the most recent earthquake.

Considering the low level of seismicity, the May 29, 2004 earthquake provides an opportunity to study source parameters of an earthquake which occurred near the Korean Peninsula. Because this event is the largest earthquake that has occurred since the modern digital seismic network was installed by KMA, it is one of the first times that detailed source parameters could be determined for an earthquake in this region. This earthquake is also important because it clearly indicates that there is active seismicity along the western edge of the Ulleung Basin (see Fig. 1). To understand the source parameters of this earthquake, we carried out modeling of regional waveforms and deconvolutions using empirical Green functions.

One interesting aspect about this earthquake is that it was followed by several events over a wide area during the subsequent 2 days (Fig. 2). However, only the $M_{L} 2.0$ event, which occurred at 04:45 on May 30, could be regarded as

Copy right(c) The Society of Geomagnetism and Earth, Planetary and Space Sciences (SGEPSS); The Seismological Society of Japan; The Volcanological Society of Japan; The Geodetic Society of Japan; The Japanese Society for Planetary Sciences; TERRAPUB. an aftershock in the immediate source region of the mainshock. We will use this $M_{L} 2.0$ event as empirical Green function for the deconvolution analyses. We used redetermined epicentral data by KMA for the May 29 event (mainshock) and for aftershock (event 2) as listed in Table 1.

\section{Regional Waveform Modeling}

We carried out waveform inversion to obtain the focal mechanism and seismic moment of the May 29, 2004 earthquake using regional data recorded by KMA on broadband stations. We used 3 component displacement waveforms bandpass filtered between $0.02 \sim 0.05 \mathrm{~Hz}$ from 8 stations. The station distributions used for the waveform modeling are shown in Fig. 2 (Solid triangles). Most stations are located westward from the hypocenter and there is only one station (ULL) to the east. Station ULJ, which will be used for deconvolution analyses, was excluded because of recording problems of the EW component. A one dimensional velocity structure determined by Kim (1995) was used for the waveform modeling and is shown in Table 2.

For the waveform inversion, we calculated synthetic Green functions for the moment tensor components, with the program of Takeo (1985), using the one-dimensional velocity structure and the source-station geometry for a fixed source depth. Using the 24 components of displacement data and synthetic Green functions, a least-squares inversion was used to determine the moment tensor components with a double-couple constraint and the total seismic moment. This procedure was repeated for various hypocentral depths of 4 to $14 \mathrm{~km}$ to find the best fitting solution. The final solution we obtained was for a depth of $8 \mathrm{~km}$ and strike $=8, \operatorname{dip}=65$, and rake $=96$. (The conjugate nodal plane has a strike $=175$, dip $=26$, and rake $=78$ ). This solution is consistent with previous focal mechanisms determined from teleseismic data and first-motion polarities (Fig. 3). 
Table 1. Earthquake parameters used in this study (data from KMA).

\begin{tabular}{ccccc}
\hline Event & Origin time (Local time) & Latitude $\left({ }^{\circ} \mathrm{N}\right)$ & Longitude $\left({ }^{\circ} \mathrm{E}\right)$ & Local magnitude \\
\hline 1 (Mainshock) & $2004.5 .29 .19: 14$ & 36.72 & 130.20 & 5.2 \\
2 (Aftershock) & $2004.5 .30 .04: 45$ & 36.66 & 130.12 & 2.0 \\
\hline
\end{tabular}

Table 2. Velocity structure used for regional waveform modeling (Kim, 1995).

\begin{tabular}{ccccc}
\hline Layer & Thickness $(\mathrm{km})$ & $V p(\mathrm{~km} / \mathrm{s})$ & $V s(\mathrm{~km} / \mathrm{s})$ & Density $\left(\mathrm{kg} / \mathrm{m}^{3}\right)$ \\
\hline 1 & 2.6 & 5.56 & 2.82 & 2600 \\
2 & 12.9 & 6.00 & 3.36 & 2700 \\
3 & 17.3 & 6.95 & 4.19 & 3000 \\
4 & $\infty$ & 7.76 & 4.63 & 3400 \\
\hline
\end{tabular}

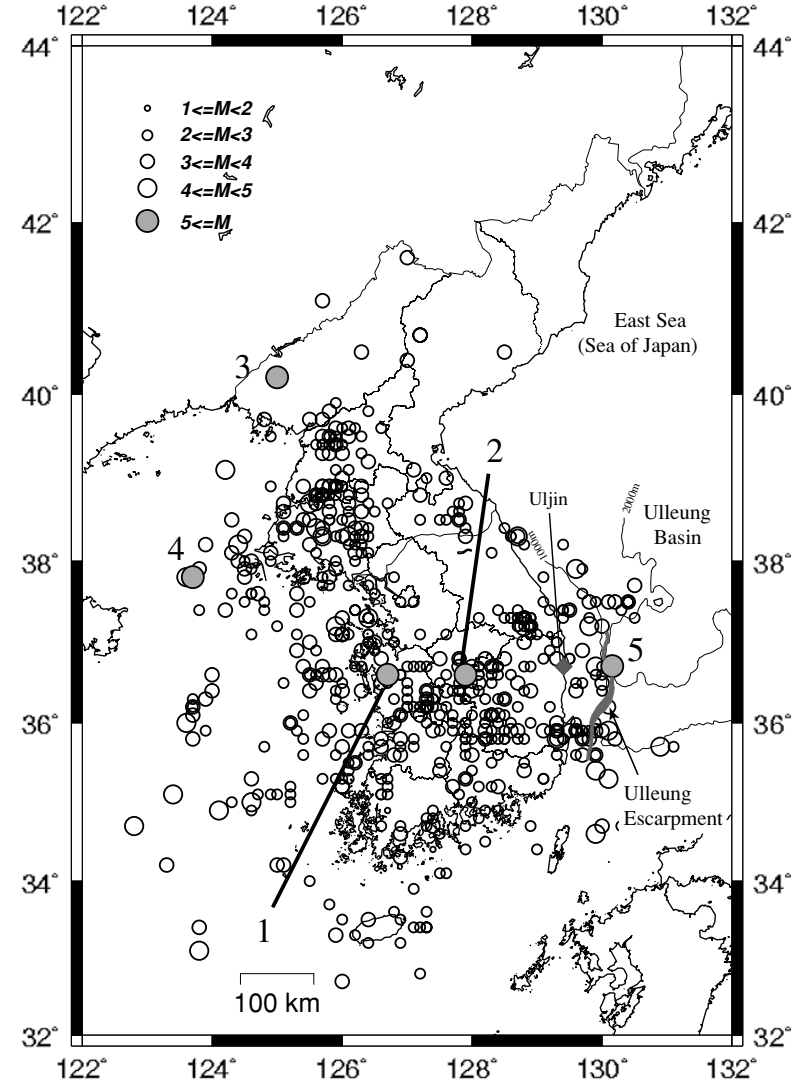

Fig. 1. Seismicity near the Korean Peninsula (1978 2004. 9, data from KMA). Solid circles indicate earthquakes with magnitude $\left(M_{L}\right)$ greater than 5. 1: 1978.9.16 $M_{L}$ 5.2, 2: 1978.10.7 $M_{L}$ 5.0, 3: 1980.1.8 $M_{L}$ 5.3, 4: 2003.3.30 $M_{L}$ 5.0, 5: 2004.5.29 $M_{L}$ 5.2. Solid diamond indicates the location of Uljin, where the highest intensity with MM V was observed. Depths of contours are 1000 and $2000 \mathrm{~m}$, roughly showing the western margin of the Ulleung Basin. Gray curved line indicates the Ulleung Escarpment (location from Chough et al., 2000).

Figure 4 shows the variance reduction between the synthetics and observed data for the range of tested depths with a maximum at $8 \mathrm{~km}$. The determination of the hypocentral depth, however, may have some inaccuracy because we used a one dimensional velocity structure and we did not consider regional variances in the structure. The velocity structure model used in this study (Kim, 1995) shows somewhat faster velocity structure compared to other models (e.g. Kim and Kim, 1983; Lee et al., 1999; Cho et al.,

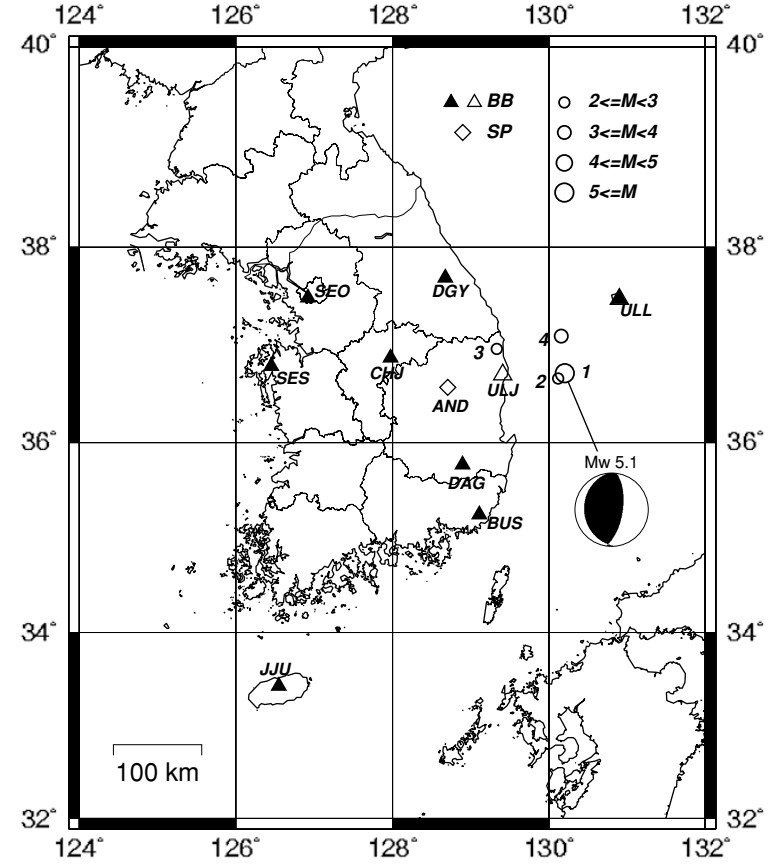

Fig. 2. Epicentral map of the May 29, 2004 earthquake and following events, and station distribution used for the analyses. Open circles indicate the epicenters of the earthquakes. 1: 5.29. 19:14 $M_{L} 5.2$ (mainshock), 2: 5.30. 04:45 $M_{L}$ 2.0, 3: 5.30. 21:45 $M_{L}$ 2.2, 4: 6.1. 20:22 $M_{L}$ 3.5. Focal mechanism shown is obtained in this study. Triangles and diamond indicate broadband and short period stations, respectively. Solid and open symbols of stations indicate stations used for regional waveform modeling and deconvolution, respectively. Station ULL is used for both analyses.

2004). This earthquake seems to have occurred near the transition zone from continental to oceanic crust at southeastern margin of Korean Peninsula (Cho et al., 2004). We used the model of Kim (1995) because the hypocenter of this earthquake seems to be located on the continental side of the transition zone and most of the paths to the stations are through the continental crust. KMA redetermined the hypocentral depth as $5.1 \mathrm{~km}$ and results by Harvard, USGS and Kang and Baag (2004) are $12.0 \mathrm{~km}, 17.0 \mathrm{~km}$ and 17.7 $\mathrm{km}$, respectively. Although there are differences due to the method and crustal structure used for hypocenter determination, the results indicate that this earthquake is a shallow crustal event. 


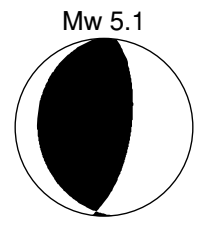

this study

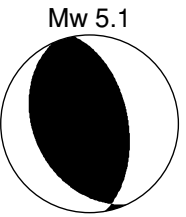

Harvard
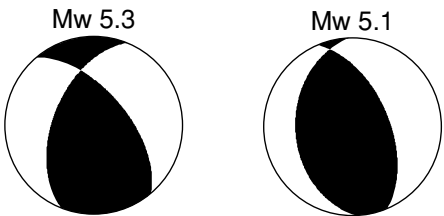

USGS Kang and Baag

Fig. 3. Focal mechanism obtained in this study compared with previous focal mechanism solutions.

The seismic moment was $5 \times 10^{16} \mathrm{~N} \cdot \mathrm{m}$, which is equivalent to Mw 5.1. Figure 5 shows synthetic waveforms and observed data. The fit is fairly good, although synthetic waveforms of station ULL to the east of the hypocenter do not fit the observed dispersed surface waves as well. This is probably due to the fact that the velocity structure toward the ocean differs from the continental side. Observed waveforms in Figure 5 have some higher frequency waves (about $0.1 \mathrm{~Hz}$ ), because we used a 2 pole Butterworth filter at 0.05 $\mathrm{Hz}$, which is not an especially sharp filter. Choosing the frequency band is a subjective process that is a trade-off between the effects of heterogeneous structure, best fitting of the waveforms, and trying to use a wide-band for a stable inversion. We tried several passbands, and it seemed that this $(0.02 \sim 0.05 \mathrm{~Hz})$ was a reasonable range for these data, although the frequency higher than $0.05 \mathrm{~Hz}$ may be strongly affected by the crustal structure.

\section{Deconvolution Using Empirical Green Func- tions}

The analysis of regional and teleseismic waveforms provides information on the focal mechanism and depth, but examination of shorter period data is necessary to look at the size and stress drop of this earthquake. We used a smaller aftershock as an empirical Green function in a deconvolution procedure to estimate the source size. In general, observed displacement waveform includes information of the source, propagation effects and instrumental response. This can be expressed as

$$
u(x, t)=s(t) * g(t) * i(t),
$$

where $u(x, t)$ is displacement, $s(t)$ is source time function, $g(t)$ is propagation function and $i(t)$ is instrumental recording function, with * indicating convolution of the time series. Using an empirical Green function $u_{1}(x, t)$, which has a short source time functions that can be approximated as a delta function $\delta(t)$, and travels the same path as the wave of mainshock, the combined effects of propagation in the crustal structure and instrumental response can be directly observed.

$$
u(x, t)=\delta(t) * g(t) * i(t)
$$

Dividing Eq. (1) by Eq. (2), the source time function of the mainshock, $s(t)$ can be directly determined,

$$
s(t)=u(x, t) / u_{1}(x, t),
$$

where the / indicates deconvolution.

As mentioned earlier, there was one event large enough and close to the mainshock that could be used as an empirical Green function. This is the $M_{L} 2.0$ earthquake that

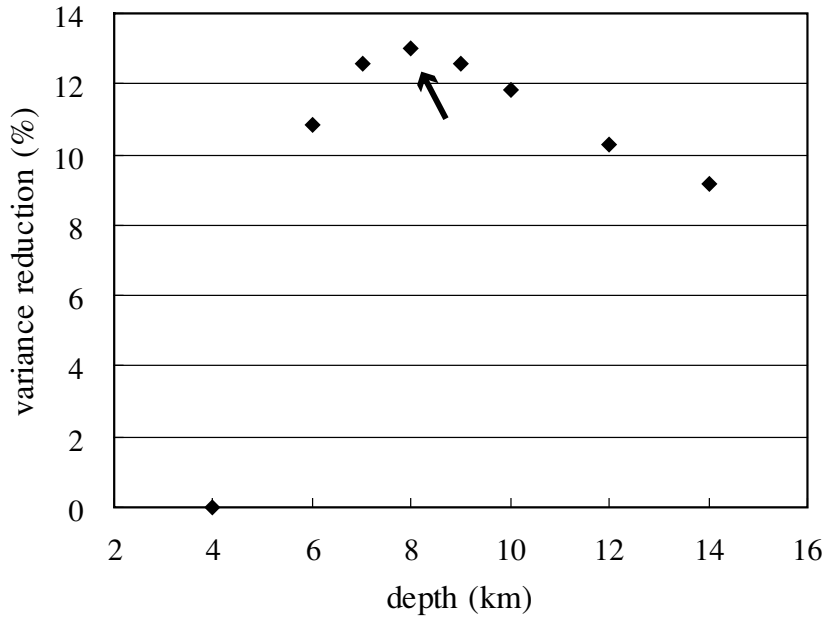

Fig. 4. Graph of tested depth versus variance reduction between the synthetics and observed data. The maximum variance reduction was obtained at $8 \mathrm{~km}$ depth.

occurred at 04:45 on May 30. Using this aftershock, we deconvolved the $P$ waveforms of one broadband (ULJ) and one short period (AND) station west of the hypocenter, and an $S$ waveform of one broadband station (ULL) east of the hypocenter (see Fig. 2 for the station distributions). We used displacement waveforms highpass filtered at $2 \mathrm{~Hz}$ at these three stations, which produced clear source time function. For the deconvolution procedure, impulse arrivals with good signal to noise are needed for both the mainshock and empirical Green function event, and this was possible for only the three closest stations.

The deconvolution was done in the frequency domain by taking a Fourier transform of a one second window of data and dividing the transform of the mainshock by that of the aftershock. Then we are able to get source time function in time domain by taking the inverse Fourier transform. A water-level criterion was applied to the transform of the aftershock, because division by small values in the spectrum of the smaller event can cause unstable values in the result (Mori and Frankel, 1990). The value for the water-level used is 0.0002 of the maximum value.

Figure 6 shows the results of the deconvolution. The hatched areas in the deconvolved waveforms indicate the source time functions and the dark lines are the rise times. The rise times are $0.275 \mathrm{~s}$ at AND, $0.27 \mathrm{~s}$ at ULJ, and 0.216 $\mathrm{s}$ at ULL. Using these values we calculated the radius of the fault $(r)$ using an expression from Boatwright (1980),

$$
r=\tau_{1 / 2} \cdot v /\left[1-\sin \theta / c\left(x_{0}\right)\right],
$$



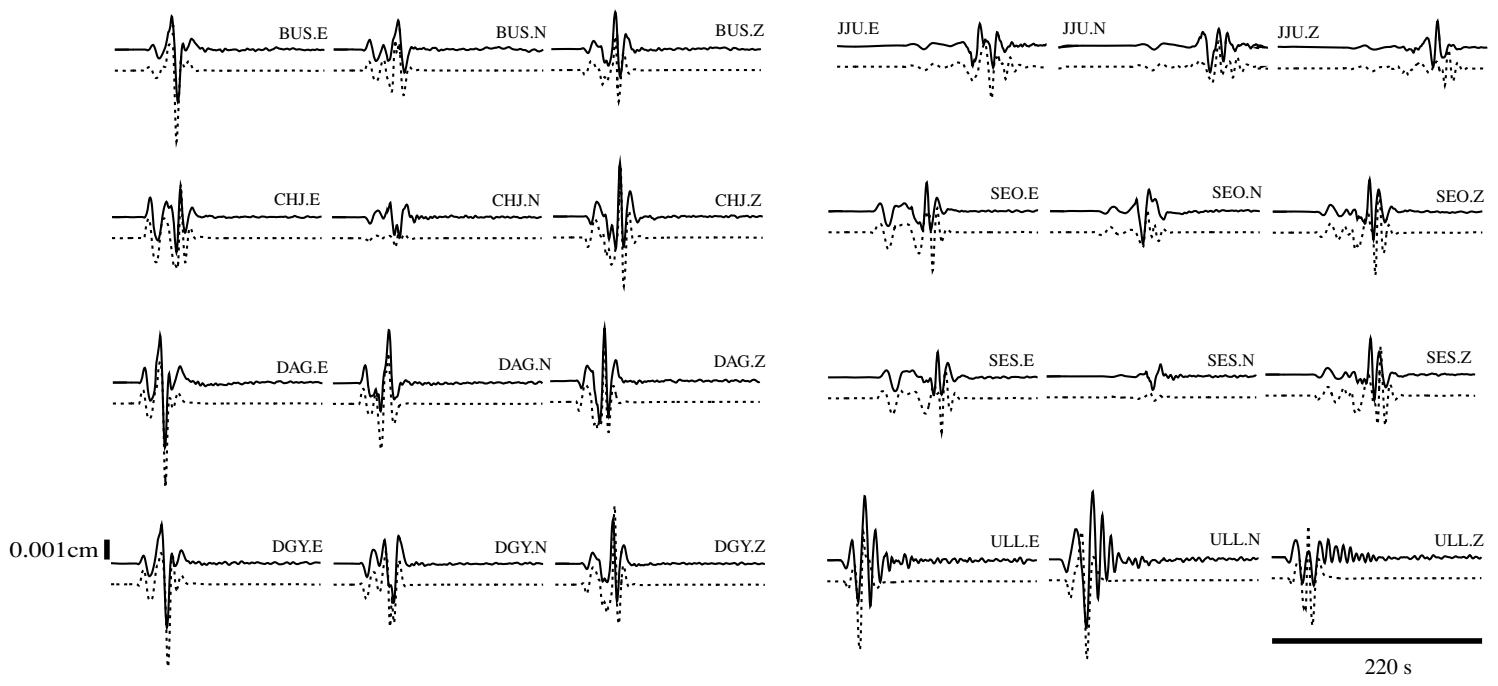

Fig. 5. Fit between the synthetics and observed data of three components of displacement. Solid and dotted lines are observed data and synthetics, respectively. Station name and component (E, N or Z) are marked above each waveform. Vertical and horizontal scale bars are $0.001 \mathrm{~cm}$ and 220 second, respectively, and scales are the same at all stations.

AND
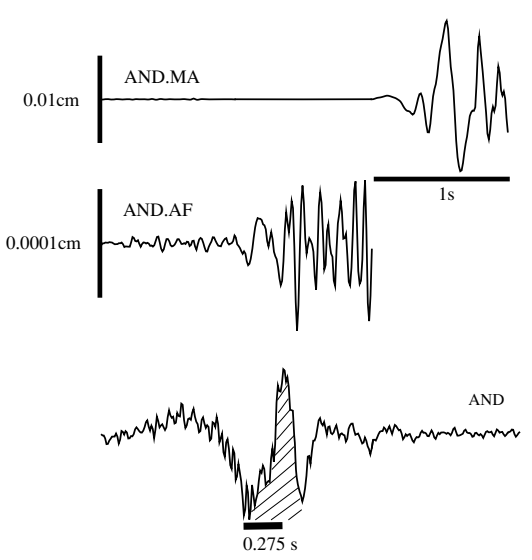

ULJ
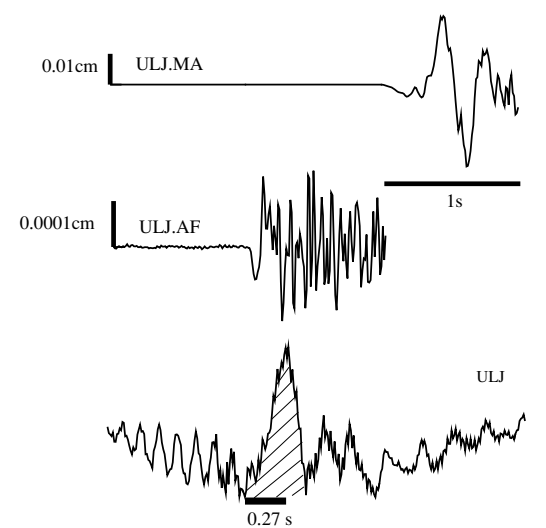

ULL

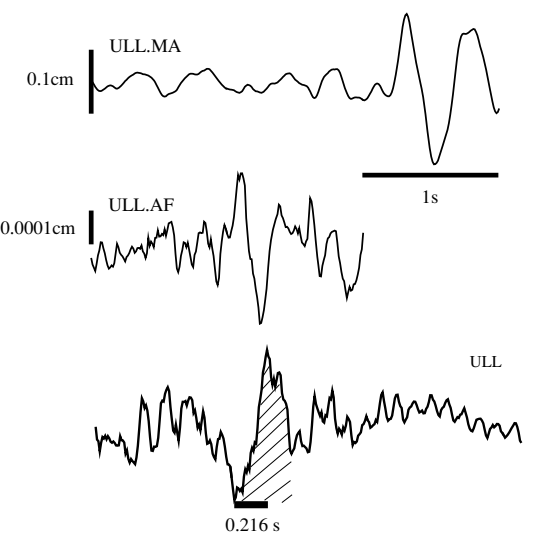

Fig. 6. Deconvolution results of three stations. Three traces in the left, those in the middle and those in the right indicate waveforms of station AND, ULJ, and ULL, respectively. In each station (three traces per each), upper trace is that of the mainshock, middle is the aftershock, and bottom is the deconvolution result. Rise time of the source time function is marked by dark line below the deconvolution result.

where $\tau_{1 / 2}$ is the rise time, $v$ is the rupture velocity, $\theta$ is the angle between the take-off direction of the $P$ wave and the fault normal, and $c\left(x_{0}\right)$ is the velocity at the source. The rupture velocity was assumed as 0.8 times the $S$ wave velocity. Since we cannot resolve which one of the two nodal planes is the fault plane, we calculated the radius for both nodal planes. The value of $\theta$ is $48^{\circ}$ for the east-dipping plane and $87^{\circ}$ for the west-dipping plane. The radius was obtained as 1.1 to $1.4 \mathrm{~km}$ when we assume the east dipping nodal plane as the fault plane. Assuming the west dipping nodal plane, the radius was obtained as 1.3 to $2.9 \mathrm{~km}$, which seems to have large variance. Then we calculated the stress drop $(\Delta \sigma)$ using the seismic moment $(M o)$ obtained from the regional waveform modeling, which is $5 \times 10^{16} \mathrm{~N} \cdot \mathrm{m}$, and the formula of Brune (1970)

$$
\Delta \sigma=(7 / 16) \cdot\left(M o / r^{3}\right)
$$

Again we tested both nodal planes. The stress drop ranged from 7.5 to $16.9 \mathrm{MPa}$ for the three stations, with an average value of 13.5 MPa for the east dipping nodal plane. For the west dipping nodal plane, the stress drop ranged from 0.9 to $9.7 \mathrm{MPa}$, with an average value of $6.6 \mathrm{MPa}$.

Kang and Baag (2004) performed modeling of $S$ wave displacement spectra at 27 local broadband stations, using best-fit model for the low-frequency asymptote of the farfield displacement amplitude of source spectrum, and obtained corner frequency, stress drop and moment magnitude at each station. Their values of stress drop are $0.1 \sim 14.9$ $\mathrm{MPa}$, with an average 5.1 MPa. It seems that the stress drop obtained in this study is consistent with the result of Kang and Baag (2004) although we used different data and analysis method.

\section{Results and Discussion}

In this study we estimated the source parameters of the May 29, 2004 South Korea earthquake $\left(M_{L}\right.$ 5.2). We car- 
ried out waveform modeling to determine the focal mechanism, hypocentral depth and seismic moment of the event. This earthquake was a reverse fault event. The hypocentral depth was obtained as $8 \mathrm{~km}$, and the seismic moment was 5 $\times 10^{16} \mathrm{~N} \cdot \mathrm{m}$, which is equivalent to Mw 5.1.

We also carried out deconvolutions using empirical Green functions, and determined the radius of the fault assuming a circular model, as well as the stress drop for each nodal plane. The radius of the fault is 1.1 to $1.4 \mathrm{~km}$ and the average stress drop is $13.5 \mathrm{MPa}$ for the east dipping nodal plane. The radius of the fault is 1.3 to $2.9 \mathrm{~km}$ and the average stress drop is $6.6 \mathrm{MPa}$ for the west dipping nodal plane. In general, shallow intraplate earthquakes have stress drop of about $10 \mathrm{MPa}$ (Lee et al., 2002a). If this earthquake occurred at a fault with the east dipping nodal plane, the stress drops are relatively high and may reflect high regional stress in this intra-plate environment.

This earthquake occurred on the western margin of the Ulleung Basin (see Fig. 1), which is located in the southwest East Sea (Sea of Japan), in the transition zone from continental to oceanic crust. Previous studies showed that there exist strike-slip, thrust and normal fault systems extending N-S to NNE-SSW offshore from the southeastern Korean Peninsula and these systems are related to the opening of the Ulleung Basin and rotation of southwestern Japan (e.g. Kim, 1992; Lee et al., 1999; Lee et al., 2002b). Lee et al. (1999) indicated the existence of a very steep eastward-dipping fault which appears to be related to strike-slip movement of the western Ulleung Basin margin, mentioned as the Ulleung Escarpment by Lee et al. (2002b). Considering these tectonic conditions and our results, this earthquake may have occurred along a N-S trending reverse fault near the Ulleung Escarpment. This recent earthquake along this large structure suggests that there is a potential for a large earthquake along the western margin of the Ulleung Basin.

Acknowledgments. We retrieved waveform data from the KMA webpage and used epicenters redetermined by KMA. We thank
Mr. Eui-Hong Hwang who helped us find the regional velocity structure and geology. We thank the EPS reviewers and editor for their helpful comments.

\section{References}

Boatwright, J., A spectral theory for circular seismic sources: simple estimates of source dimension, dynamic stress drops, and radiated energy, Bull. Seism. Soc. Am., 70, 1-28, 1980.

Brune, J. N., Tectonic stress and the spectra of seismic shearwaves from earthquakes, J. Geophys. Res., 75, 4997-5009, 1970.

Cho, H.-M., H.-J. Kim, H.-T. Jou, and J.-K. Hong, Transition from rifted continental to oceanic crust at the southeastern Korean margin in the East Sea (Japan Sea), Geophys. Res. Let., 31, L07606, doi:10.1029/2003GL019107, 2004.

Chough, S. K., H. J. Lee, and S. H. Yoon, Marine geology of Korean Seas, 202 pp, Elsevier Science B. V., Amasterdam, 2000.

Kang, T.-S. and C.-E. Baag, The 19 May 2004, Mw=5.1, offshore Uljin earthquake, Korea, Geoscience J., 8, 115-123, 2004.

Kim, I.-S., Origin and tectonic evolution of the East Sea (Sea of Japan) and the Yangsan Fault system: A new synthetic interpretation, Jour. Geol. Soc. Korea, 28, 84-109, 1992 (in Korean with English abstract).

Kim, S. J. and S. G. Kim, A study on the crustal structure of South Korea by using seismic waves, J. Korean Inst. Mining Geol., 16, 51-61, 1983 (in Korean with English abstract).

Kim, S. K., A study on the crustal structure of the Korean Peninsula, Jour. Geol. Soc. Korea., 31, 393-403, 1995 (in Korean with English abstract).

Lee, G. H., H. J. Kim, M. C. Suh, and J. K. Hong, Crustal structure, volcanism, and opening mode of the Ulleung Basin, East Sea (Sea of Japan), Tectonophysics, 308, 503-525, 1999.

Lee, S. H., S. K. Chough, G. G. Back, and Y. B. Kim, Chirp (2-7-kHz) echo characters of the South Korea Plateau, East Sea: styles of mass movement and sediment gravity flow, Mar. Geol., 184, 227-247, 2002 b.

Lee, W. H. K., H. Kanamori, P. C. Jennings, and C. Kisslinger, Earthquake stress drops and plate boundary stresses, in International Handbook of Earthquake \& Engineering Seismology, edited by W. H. K. Lee, H. Kanamori, P. C. Jennings, and C. Kisslinger, pp. 548-551, Academic press, London, 2002a.

Mori, J. and A. Frankel, Source parameters for small events associated with the 1986 North Palm Springs, California, earthquake determined using empirical Green functions, Bull. Seism. Soc. Am., 80, 278-295, 1990 .

Takeo, M., Near-field synthetic seismograms taking into account the effect of anelasity-The effects of anelastic attenuation on seismograms caused by a sedimentary layer, Pap. Meteo. Geohys., 36, 245-257, 1985 (in Japanese).

S.-C. Park (e-mail: suncheon@eqh.dpri.kyoto-u.ac.jp), and J. Mori 